\title{
Modified Archie's parameters for estimating water saturation for carbonate reservoir in north of Iraq
}

\author{
Hayder A. Jumaah ${ }^{1}$
}

Received: 7 January 2021 / Accepted: 6 August 2021 / Published online: 21 August 2021

(c) The Author(s) 2021

\begin{abstract}
Archie's parameters, cementation factor $(m)$, saturation exponent $(n)$ and tortuosity factor $(a)$, are general factor that have effects on water saturation magnitude, due to their sensitivity to pores distribution, lithofacies properties and wettability, particularly in carbonate reservoirs. Water saturation magnitude has a direct effect in estimating initial oil-in-place values, and inaccuracy in its values will lead to huge impact errors in initial oil-in-place values, so it would affect the economics of field management and development plans. In this paper, the main objective was to investigate the impact of using conventional and modified Archie's parameters in the determination of water saturation from well log interpretation for Tertiary reservoir in Khabaz oil field, a heterogenous carbonite reservoir in the north of Iraq which was affected by different digenesis processes that impacted the reservoir quality. Tertiary reservoir of Khabaz field consists of five geological units (A, B, C, $\mathrm{D}$ and E), and the selected well penetrated the top of the reservoir at $2200.5 \mathrm{~m} \mathrm{RTKB}$ and passed through five geological units and reached total depth at $2348 \mathrm{~m}$ RTKB. The geothermal gradient of the field was $1.12{ }^{\circ} \mathrm{F}$ per $100 \mathrm{ft}$, and formation water resistivity $(R w)$ was about $0.029 \Omega \mathrm{m}$. Water saturation was at first estimated from resistivity logs by Archie model with conventional known values of parameters $(a, m$ and $n)(1,2$ and 2), respectively, and then Archie's parameters were modified and determined by graphical technique of Pickett plot for each geological unit to estimate water saturation. Finally, the results show the water saturation value was more sensitive for Archie's parameter in low-porosity and high-clay-volume zone, but less sensitive in clean high-porosity zone, and water saturation values determined by modified Archie model were less about $18.5 \%$ at mean than their value by using conventional Archie's parameters.
\end{abstract}

Keywords Reservoir characterization · Archie's parameters $\cdot$ Carbonate reservoir $\cdot$ Khabaz oil field

\section{Introduction}

Estimation of the hydrocarbons in place of a reservoir by volumetric methods requires petrophysical data including porosity and water saturation (Bose et al. 2009). Archie in 1941 found an empirical equation for estimating water saturation in consolidating sandstone related to some formation parameters such as porosity and formation resistivity (Kennedy et al. 2019). At first, Archie equation was used for estimating water saturation in reservoir rocks with significant attributes such as clean, homogenous and thin bed, but these properties in heterogenous carbonate rocks may be unrecognized, so water saturation magnitude may be deviated and

Hayder A. Jumaah

haiderashour@yahoo.com

1 Ministry of Oil, North Oil Company, Kirkuk, Iraq be overvalued (Alao et al. 2013). Hydrocarbon volumes in place in the evaluation phase directly have effect on field management and development plans in the future (Ramamoorthy et al. 2019)

For heterogenous carbonate reservoirs, estimating accurate hydrocarbon volumes in place in the evaluation phase required accuracy of water saturation value (Mathur et al. 2020). For the given reservoir, accuracy of water saturation depends on the accuracy of Archie's parameters of cementation exponent $(m)$, saturation exponent $(n)$ and the rock consolidation factor (a) (AL-Awad 2001). The conventional procedure to determine modified Archie equation parameters is by cross-plot techniques (Krygowshi 2012).

Historically, Pickett plot was used as a robust technique for estimation Archie's parameters in log interpretation (Olusola and Aguilera 2018). Plotting formation resistivity factor (FR) versus core or log porosity on the $\log$-log paper is used to find ' $a$ ' and ' $m$ ' values. The value of ' $m$ ' is the 
slope, and ' $a$ ' is the intercept. However, in carbonate rocks, most of the points are scattered and one slope cannot be driven. The same situation occurs when water saturation is plotted against resistivity index (IR) to find the value of $(n)$ (Talabani et al. 2000). Also, petroleum literature contains many reports of the results determining Archie's parameters and related water saturation distribution in the pores. Pickett in 1973 provided graphical solutions to Archie's equation which can be used to quick prediction of water saturation or to predict Archie equation parameters used in interpretation methodologies by the following equation (Krygowshi 2012):

$\log R t=-m \times \log \emptyset+\log (a \times R w)-n \times \log S w$.

For the water-saturated zone $(S w=100 \%)$, the above equation reduces to:

$\log R t=-m \log \emptyset+\log (a R w)$

where $S w$ : water saturation (fraction). $R w$ : formation of water resistivity (ohm-m).Rt: true formation resistivity (ohm-m). And $a, n$ and $m$ : Archie's parameters.

Bigges and Morris in 1968 and Buckles in 1965 observed that zones at irreducible water saturation ( $\mathrm{Swi}$ ) in a formation display a constant bulk volume fraction of water (Krygowski and Cluff 2012):

$\mathrm{BVW}=\emptyset \times S w i$.

$\mathrm{BVW}=$ minimum implies $S w$ irreducible, or no water production

Swi $\times \emptyset=c$

where $c$ is a constant.

For irreducible water saturation zones, $S w$ was replaced by $S w i$ in Eq. (1); then, it becomes

$\log R t=(n-m) \log \emptyset-\log \left(\frac{a R w}{C^{n}}\right)$.

The above equation shows that for plot $R t$ versus $\varnothing$ on $\log -\log$ paper, the points corresponding to the zones at irreducible water saturation define a linear trend of slope $(n-m)$ and the intercept at $(\varnothing=1)$ is

$\log \frac{a R w}{C^{n}}$

\section{Area of study and field description}

Khabaz field is one of the important Iraqi oil field with several pay zones like to most of the carbonate oil fields in north of Iraq. It is located in the northeast of Iraq at approximately $20 \mathrm{~km}$ northwest of Kirkuk city, surrounded by three oil fields Baba dome in Kirkuk field from northeast and
Jumbour field from southeast and Bai Hassan oil field from northwest as shown in Fig. 1. Khabaz structure was first discovered through seismic investigation in 1958 (Al-Qayim et al. 2010). The structure consists of single asymmetrical small subsurface anticline dome sweeping to south direction with depth its northeast flange dipper than the southwest flange and consists of three main hydrocarbon reservoirs (Al Kattan et al. 2018).

1. Tertiary Reservoir.

2. Cretaceous Upper Qamchuqa (Mauddud) Reservoir.

3. Cretaceous Lower Qamchuqa (Shuaiba) Reservoir.

Sedimentology and paleogeography of the Kirkuk region of Iraq, were established by studying the Zagros outcrops at the northeast and the numerous petroleum fields in the southwest of the region, and the main features of this evolution were summarized by AlShdidi et al. in 1995 and by Sharland et al. (Ghafor et al. 2011).

In this paper, the impact of Archie's parameters in estimation of water saturation was studied for a well that penetrated the Tertiary reservoir, the Tertiary oil reservoirs in the Khabaz oil developed within Cenozoic geological era and was referred to here as the Mesopotamian basin in Paleocene Eocene time (Aqrawi et al. 2011), and the main pay reservoir of Tertiary reservoir thickness ranges between 150 and $170 \mathrm{~m}$; it encompasses five beds from top to bottom as illustrated in Table 1.

Jeribe formation located within middle Miocene is mainly composed of porous dolomite, with nodules of anhydrite and streaks of dolomitic and marly limestone, But Anah, AnahAzkand and Azkand Ibrahim located within lower Miocene. Anah and Anah-Azkand are mostly composed of crystalline dolomitic limestone with some marls. Otherwise, Azkand is generally composed of dolomitic limestone, porous vuggy dolomite, so it represents the best productive formation within Tertiary reservoir. As for Azkand Ibrahim, it is composed of highly recrystallized limestone and represents the worst petrophysical formation within productive zone shown in Fig. 2 (Al Kattan et al. 2018).

\section{Results}

Investigation of impact of Archie's parameter in water saturation in heterogeneous carbonate reservoir was done using $\log$ data, lithology and fluids type. The selected well represents an example well that includes the needed data for the study: it penetrated the top of the reservoir at $2200.5 \mathrm{~m}$ and passed through five geological units (A, B, C, D and E) and reached the total depth at $2348 \mathrm{~m}$. Well logs for the five geological units (A, B, C, D and E) indicate that oil water contact in the well located at $2300 \mathrm{~m}$ RTKB and the 
reservoir rocks are generally Dolomitic Limestone in first three units with a few small intervals of anhydrite in unit (A) and the most of unit (E) composed compacted crystalline limestone. Gamma ray log magnitude response for how much the reservoir rock is clean was essential for estimating the amount of clay within rock, and clay volume estimated by Gamma ray method referenced the maximum clay volume about $23 \%$ located within unit (A) and minimum value about $9 \%$ within unit (B).
Table 1 Tertiary reservoir main units

\begin{tabular}{lll}
\hline Formations & Referenced as & Thickness (m) \\
\hline Jeribe & Unit A & 25 \\
Anah & Unit B & 8 \\
Anah-Azkand & Unit C & 17 \\
Azkand & Unit D & 63 \\
Azkand Ibrahim & Unit E & 60 \\
\hline
\end{tabular}

Fig. 1 Area of study (Al-Qayim et al. 2010)

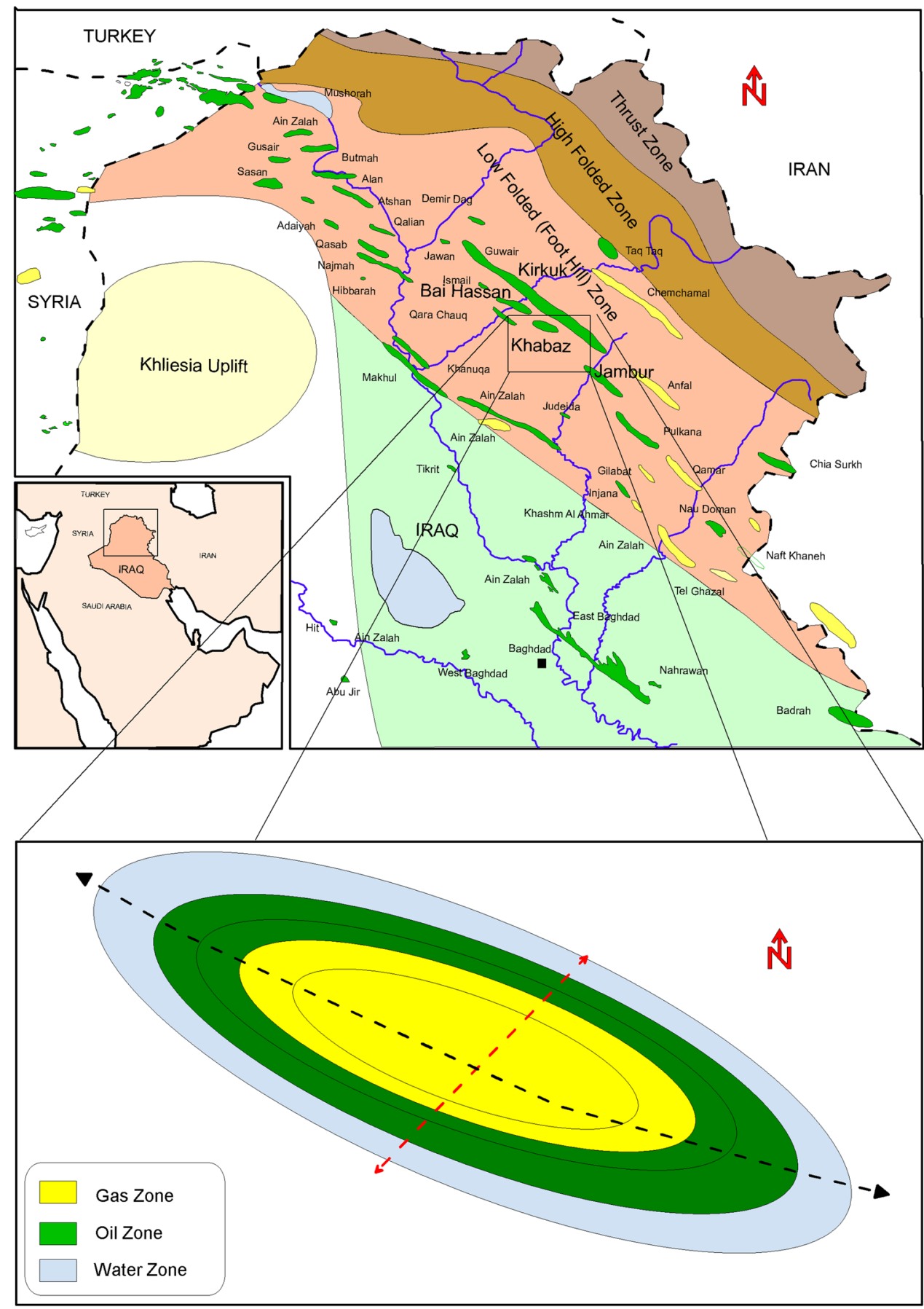




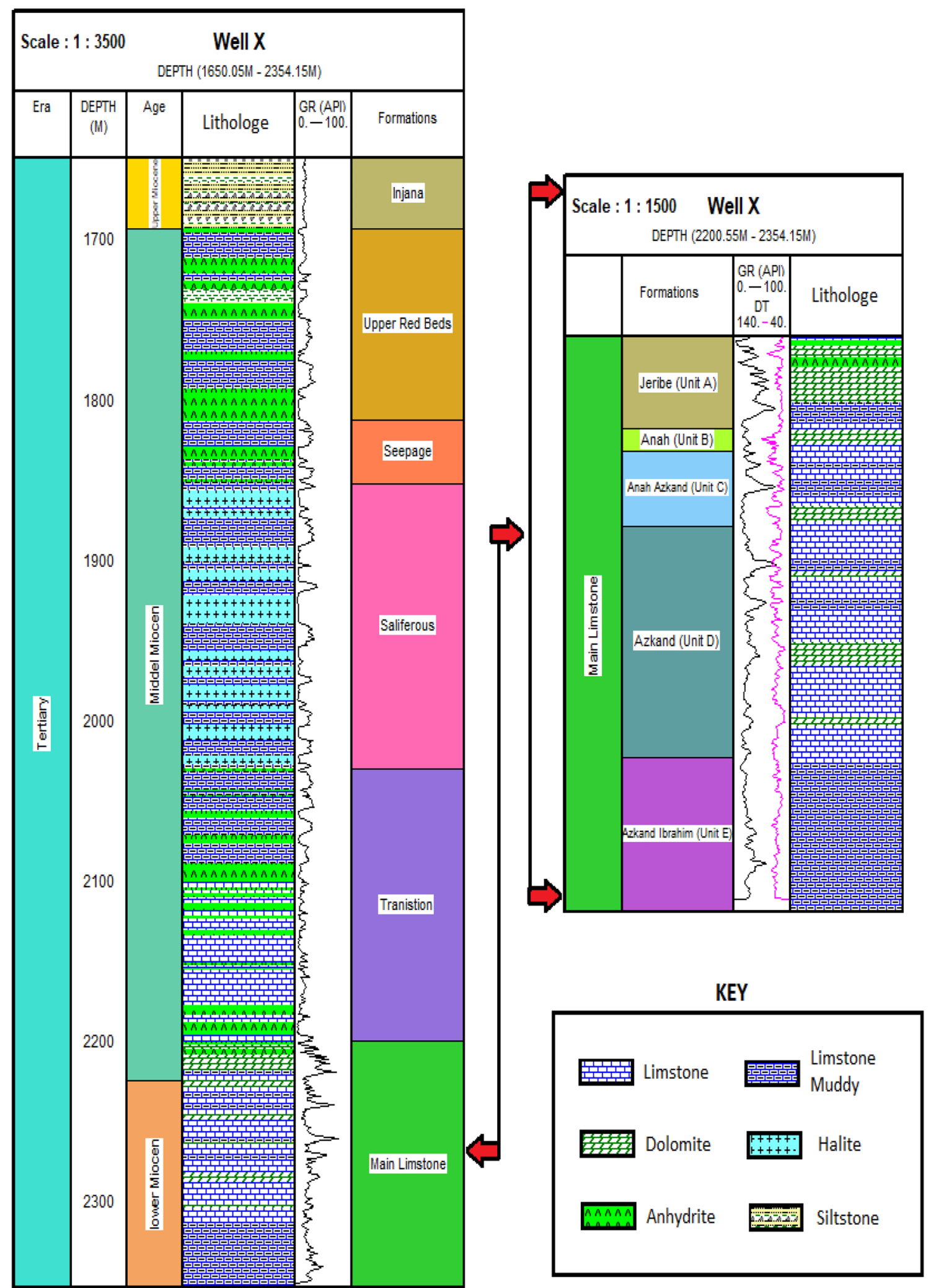

Fig.2 Stratigraphy of Tertiary reservoir of Khabaz field 


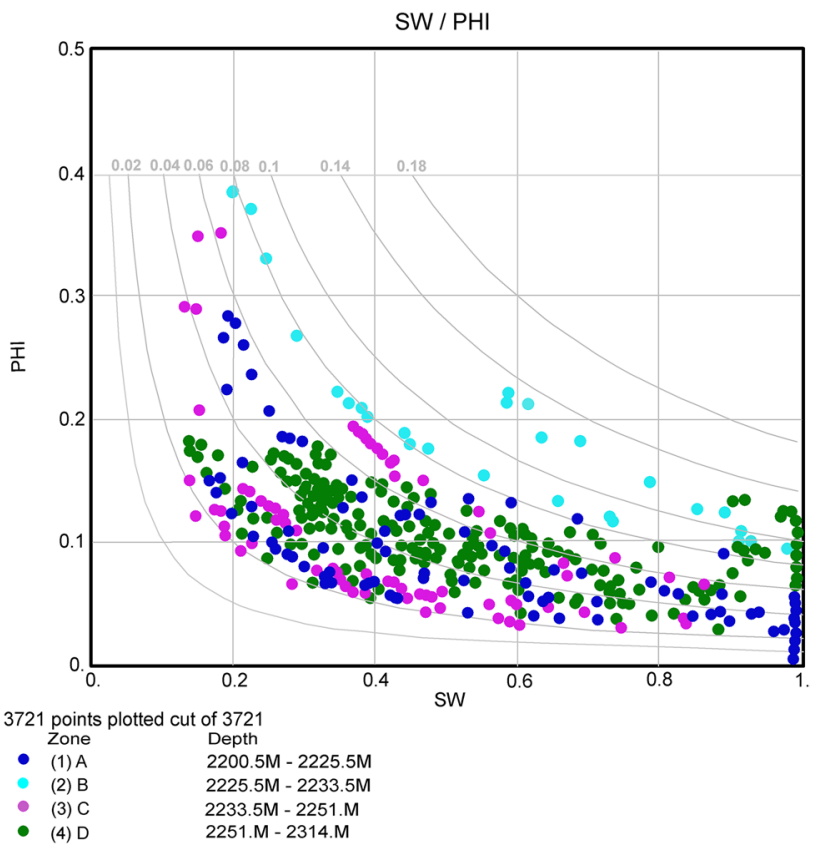

Fig. 3 Irreducible water saturation zone bulk volume by Buckles plots

Porosity generally estimated from (density-neutron) logs and corrected to clay volume to be use as effective porosity in Archie equation for estimate water saturation. Porosity model showed the maximum value of effective porosity about $22 \%$ within unit (B) and minimum value about $5 \%$ within unit (E). Formation water resistivity conducts electricity because it is a function of salinity and temperature. Depending on geothermal gradient $1.12 \mathrm{~F}$ per $100 \mathrm{ft}$ in the field and formation water salinity of 140,000 ppm from DST test at water-bearing zone, the formation's water resistivity (Rw) was calculated to be about $0.029 \Omega \mathrm{m}$ at bottom hole temperature. Water saturation was at first estimated from resistivity logs by Archie model depending on the conventional known values of parameters $(a, m$ and $n),(1,2$ and 2 ), respectively, but these values were considered partially for saturated hydrocarbon-bearing zone of shale-free sandstones; to use it for the studied well, Pickett plot was used for predicted specific parameter for each geological unit.

Archie's parameters $(a, m$, and $n)$ were estimated for four reservoir units individually penetrated by well except unit (E) due to its water-bearing zone proven by DST test, unit (B) combined with unit (C) because the interval is not too large. By graphical pattern techniques of Pickett plot, the

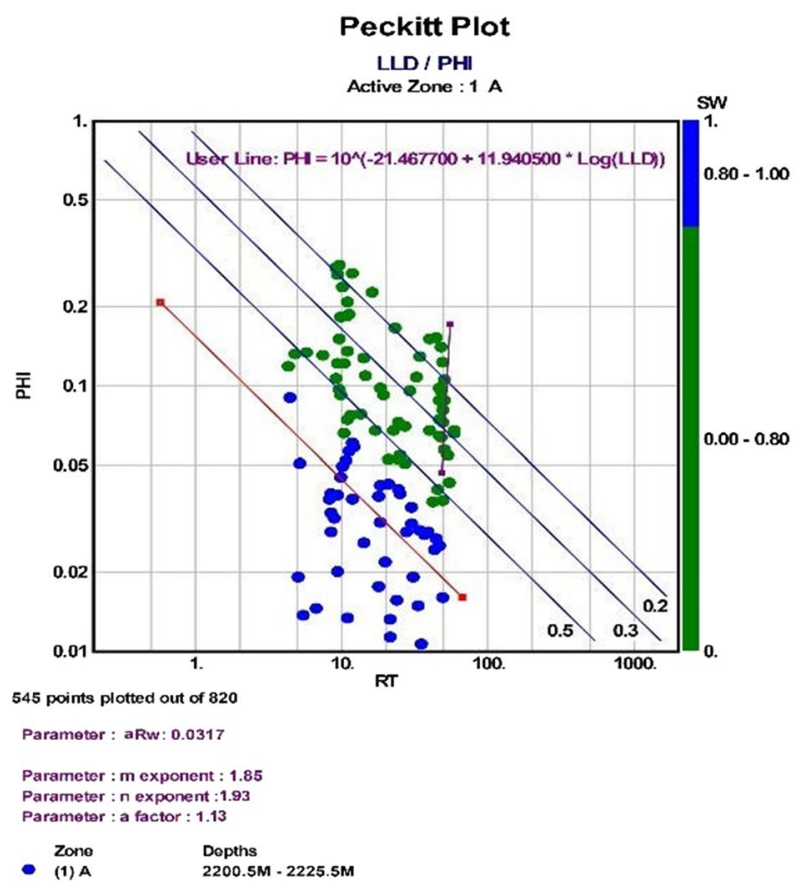

Fig. 4 Pickett plot result for unit A

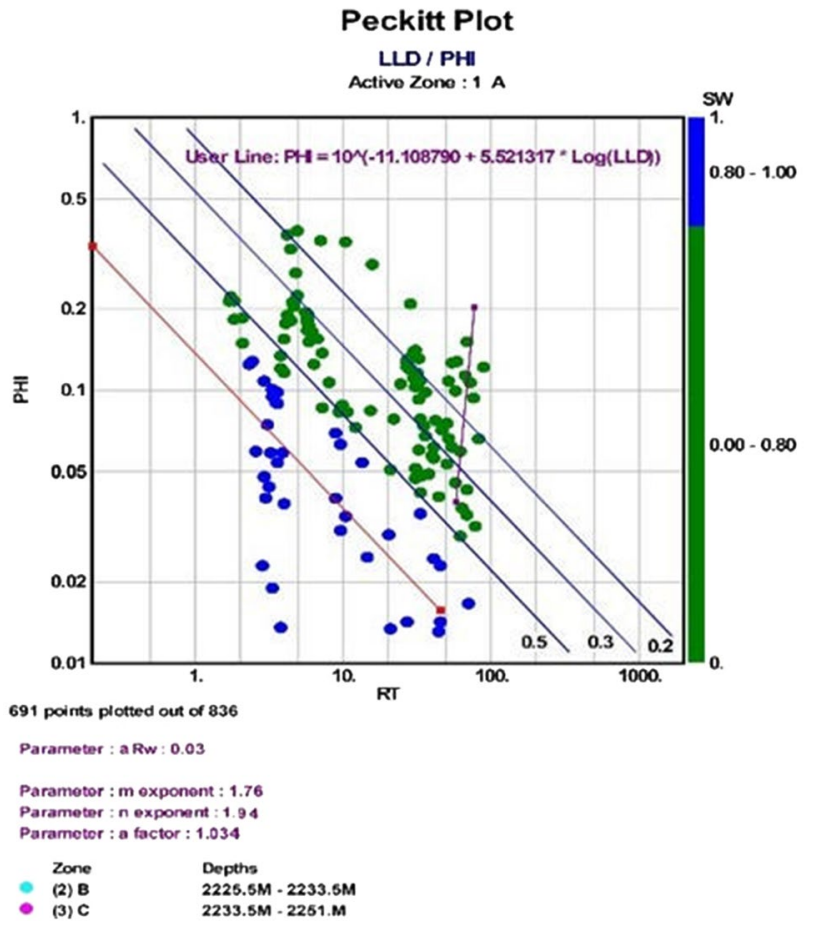

Fig. 5 Pickett plot result for units B and C 
Table 2 Archie's modified parameter result

\begin{tabular}{llll}
\hline Zone & $a$ & $m$ & $n$ \\
\hline A & 1.093 & 1.85 & 1.93 \\
B and C & 1.034 & 1.76 & 1.94 \\
D & 1.093 & 1.83 & 1.94 \\
\hline
\end{tabular}

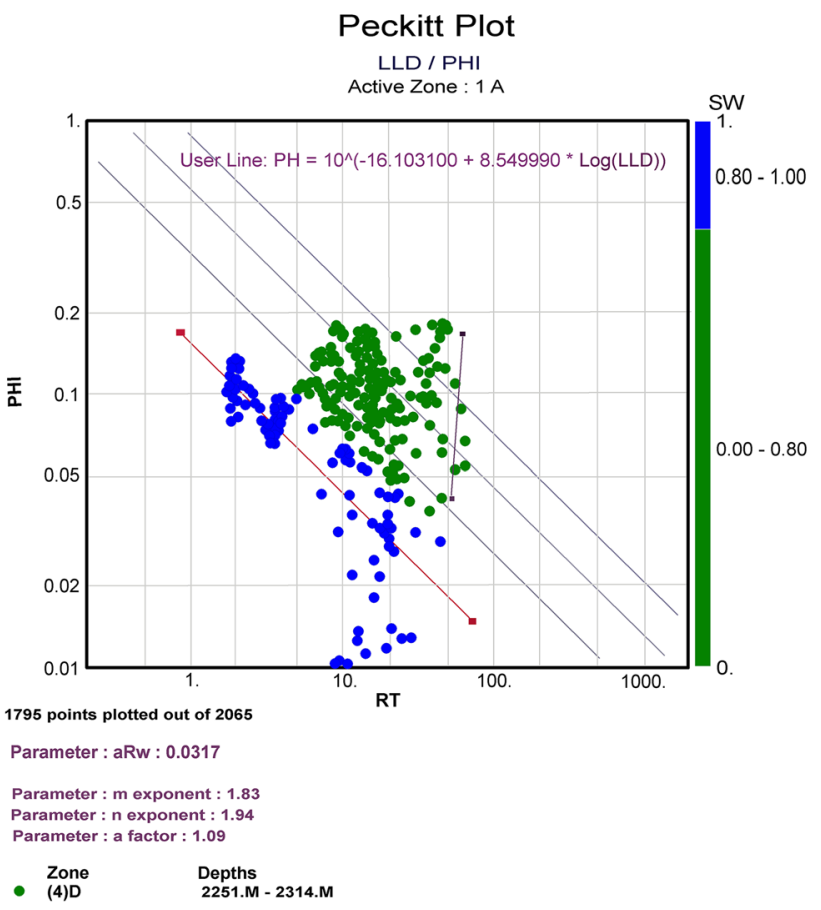

Fig. 6 Pickett plot result for unit D

parameters ( $a$ and $m$ ) were picked at $100 \%$ of water saturation zone. Saturation exponent $(n)$ estimation requires irreducible bulk volume (BVW) values. Buckles plot a useful approach gives a direct value of irreducible water saturation zone bulk volume between 18 and $20 \%$ as shown in Fig. 3.

Finally, by crossing bulk volume value with $100 \%$ water saturation line as shown in Figs. 4, 5 and 6 all Archie's parameters provided for each geological unit are illustrated in Table 2.
Water saturation estimated using both conventional and modified Archie methods is shown in Fig. 7. And the summary of saturation values by two methods with petrophysical properties is given in Table 3 .

According to typical results of two water saturation models profiles, water saturation values are shown to be more sensitive for Archie's parameters in carbonate rocks reservoir and its value is deduced from modified Archie's graphical less than from conventional method in generally, but individually as results summarized in Table 3, the unit B's water saturation is shown to be less sensitive for Archie's parameter and its highest value of porosity of about $22 \%$ and lowest value in clay volume 9\% were observed; otherwise, A and D are shown to be more sensitive for Archie's parameter than other units with remarkable value of $13 \%$ for porosity and $23 \%$ and (14) \% in clay volume, respectively, but investigation of impact of Archie's parameter in the unit $\mathrm{C}$ was shown to be moderately sensitive with average porosity and clay volume $(15) \%$. The limitation behind this work is its need to compare the results with core date, but the main advantages of the used technique is that it does not need experimental work.

\section{Conclusion}

- In this paper, investigation of impact of Archie's parameter in estimating water saturation was done for heterogenous carbonite reservoir by using graphical method depending on well log data recoded for different geological units.

- An exact value of Archie's parameters is necessary for a good log interpretation to a precise water saturation. Graphical technique allows quick determination of Archie's parameters without the need for numerical calculations.

- Water saturation value is shown to be more sensitive for Archie's parameter in low-porosity and high-clay-volume zone, but less sensitive in clean high-porosity zone. 


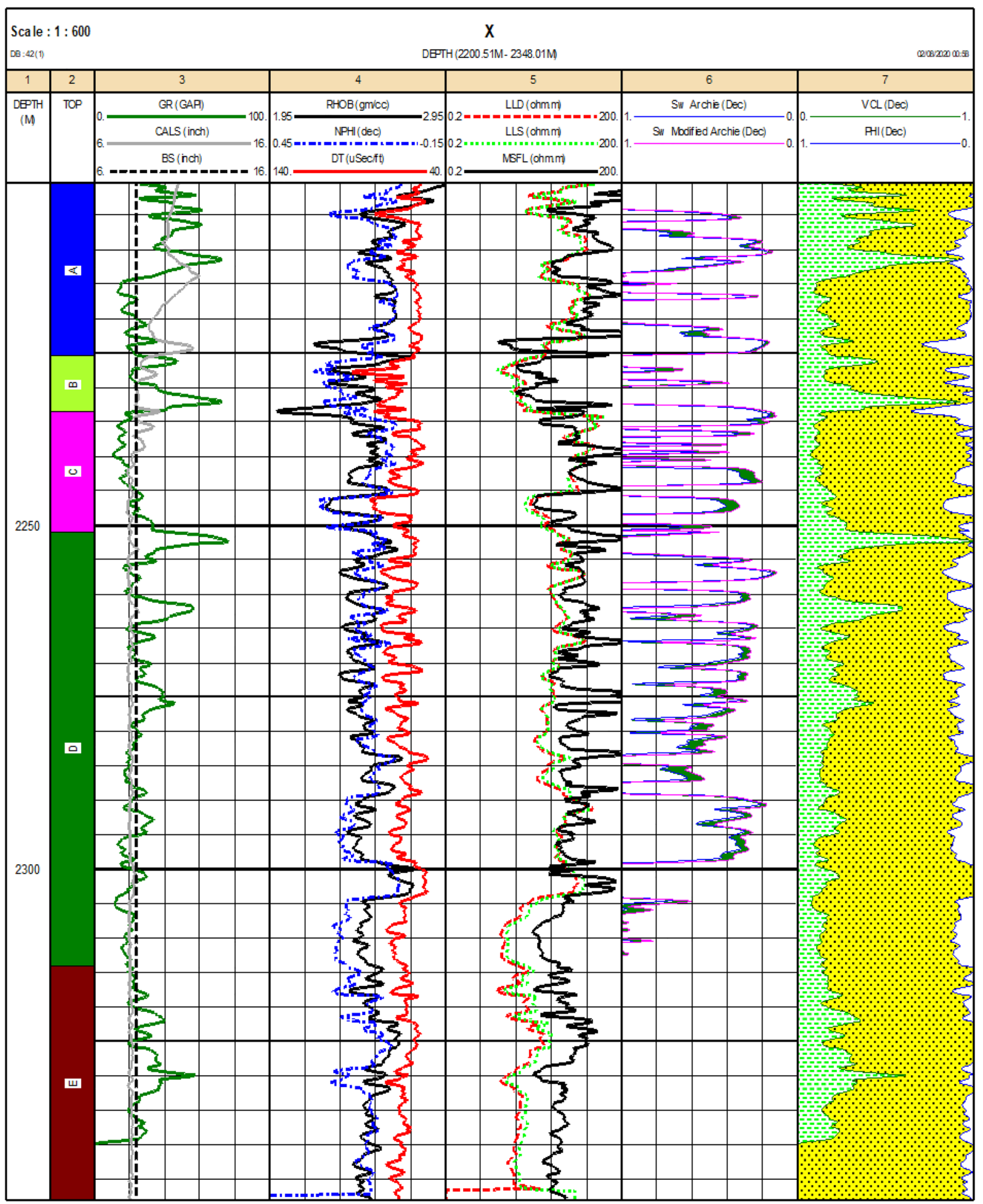

Fig. 7 Water saturation estimated using both the conventional and modified Archie methods 
Table 3 Summary of water saturation result with petrophysical properties for each unit

\begin{tabular}{lllll}
\hline Unit & $S w$ Archie & $\begin{array}{l}S w \text { modified } \\
\text { Archie }\end{array}$ & Porosity & Clay volume \\
\hline A & 0.47 & 0.24 & 0.13 & 0.23 \\
B & 0.64 & 0.66 & 0.22 & 0.09 \\
C & 0.39 & 0.27 & 0.15 & 0.15 \\
D & 0.52 & 0.30 & 0.13 & 0.14 \\
E & 1 & 1 & 0.05 & 0.1 \\
\hline
\end{tabular}

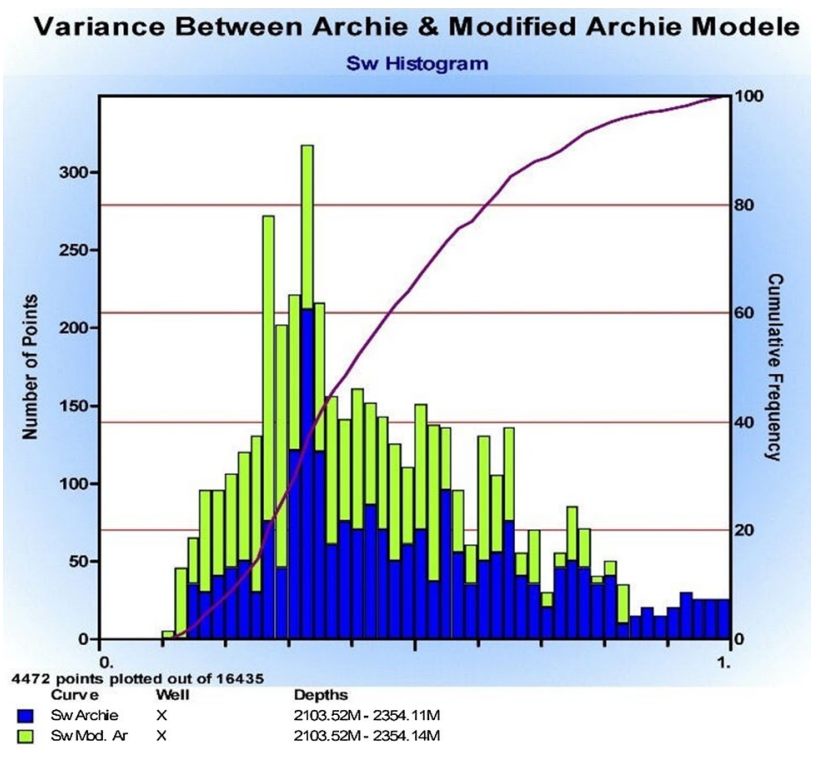

Fig. 8 Histogram of water saturation values

- The result of water saturation magnitude determined by Archie's and modified Archie's parameter shows a remarkable variance in values. Histogram of water saturation values in Fig. 8 was deduced from modified Archie's less than from the conventional method, and also statistics shows water saturation by modified model less than by conventional and the variance was about $18.5 \%$ in the mean, as illustrated in Table 4.

- Log interpretation shows the reservoir rocks are generally Dolomitic Limestone in first three units with a few small intervals of anhydrite in unit (A) and the most of unite (E) is composed of compacted crystalline limestone; the maximum clay volume about (23) \% located within unit (A) and minimum value about (9) \% within unit (B) and maximum value of effective porosity of about $22 \%$ within unit (B) and minimum value of about $5 \%$ within unit (E).

Funding The author received no financial support for the research, authorship, and/or publication of this article.

Open Access This article is licensed under a Creative Commons Attribution 4.0 International License, which permits use, sharing, adaptation, distribution and reproduction in any medium or format, as long as you give appropriate credit to the original author(s) and the source, provide a link to the Creative Commons licence, and indicate if changes were made. The images or other third party material in this article are included in the article's Creative Commons licence, unless indicated otherwise in a credit line to the material. If material is not included in the article's Creative Commons licence and your intended use is not permitted by statutory regulation or exceeds the permitted use, you will need to obtain permission directly from the copyright holder. To view a copy of this licence, visit http://creativecommons.org/licenses/by/4.0/.

\section{References}

Al Kattan W, Al Jawad SN, Jomaah HA (2018) Cluster Analysis approach to identify rock type in tertiary reservoir of Khabaaz oil field. Iraqi J Chem Petrol Eng 19(2):9-13

Alao PA, Ata AI, Nwoke CE (2013) Subsurface and petrophysical studies of Shaly-Sand reservoir targets in Apete Field, Niger Delta. Int Scholarly Res Not 2013(102450): 11

AL-Awad M (2001) "Evaluating uncertainty in archie's water saturation equation parameters determination methods," In: Society of petroleum engineers, SPE Middle East Oil Show, March, Manama, Bahrain, pp 17-20

Al-Qayim B, Qadir F, Al-Biaty F (2010) Dolomitization and porosity evaluation of the Cretaceous Upper. GeoArabia 4(15):49-76

Aqrawi AAM, Goff JC, Horbury AD, Sadooni FN, "Cinozoic (2011) Stratigraphy. Tectonic and Basin Devlopment". In: The petroleum geology of Iraq, UK, Scientific Press, pp. 161-238

Bose S, Myers MT, Chen P, Thakur G (2019) "Application of an Integrated Petrophysical Modeling to Improve Log Based Reservoir Characterization and Oil In-Place Estimate of a Fresh Water Shaly Sand Reservoir,". In SPWLA 60th annual logging symposium, June, The Woodlands, Texas, USA, pp 15-19

Ghafor I, Karim K, Sissakian V (2014) Biostratigraphy of oligocene succession in the high folded Zone, Sulaimani, Kurdistan region, Northeastern Iraq. Arab J Geosci 7. https://doi.org/10.1007/ s12517-013-1067-2

Table 4 Statistics and the variance results of water saturation by modified model and conventional Archie's parameters

\begin{tabular}{|c|c|c|c|c|c|c|c|c|c|c|c|}
\hline Curve & Well & Zone & Top (m) & Bottom (m) & Min & Max & Mean & Mode & $P 10$ & $P 50$ & $P 90$ \\
\hline Sw Archie & $X$ & ALL & 2103 & 2354 & 0.1421 & 1 & 0.49368 & 0.33 & 0.2569 & 0.4449 & 0.8002 \\
\hline Sw Modified Archie & $X$ & ALL & 2103 & 2354 & 0.1186 & 1 & 0.40189 & 0.27 & 0.207 & 0.3676 & 0.6425 \\
\hline Variance $\%$ & & ALL & 2103 & 2354 & 16.5 & 0 & 18.5 & 18.1 & 19.4 & 17.3 & 19.7 \\
\hline
\end{tabular}


Kennedy D, Garcia F (2019) Tutorial: introduction to resistivity principles for formation evaluation: a tutorial primer. PetrophysicsThe SPWLA J Formation Evalu Reser Descr 60(2): 208-227

Krygowski DA, Cluff RM (2012) Pattern recognition in a digital age: a gameboard approach to determining petrophysical parameters. In: AAPG annual convention and exhibition, Long Beach, California, April, pp. 22-25

Mathur A, Ali, S, Ali M, Belanger C, Ravi VR (2020) "Measuring hydrocarbon gas properties for accurate gas-in-place calculations for unconventional gas reservoirs,". In: SPE/AAPG/SEG unconventional resources technology conference, Virtual

Olusola B, Aguilera R (2018) "Determination of thermal maturity and maturation trajectories in shale petroleum reservoirs with the use of modified pickett plots,". In: SPE Canada unconventional resources conference, Calgary, Alberta, Canada
Ramamoorthy R, Ramakrishnan TS, Dasgupta S, Raina I (2019) "Towards a petrophysically consistent implementation of archie's equation for heterogeneous carbonate rocks,". In: SPWLA 60th annual logging symposium, June, The Woodlands, Texas, USA, pp 15-19

Talabani S, Boyd D, El Wazeer F, Al Arfi S (2000) "Validity of Archie Equation in Carbonate Rocks,". In: Abu Dhabi international petroleum exhibition and conference, October, Abu Dhabi, United Arab Emirates, pp 13-15

Publisher's Note Springer Nature remains neutral with regard to jurisdictional claims in published maps and institutional affiliations. 